\title{
The Social Sciences of Sport: Assumptions, Associations, and Conferences
}

Authors' contribution:

A) conception and design of the study

B) acquisition of data

C) analysis and interpretation of data

D) manuscript preparation

E) obtaining funding

\section{Jerzy Kosiewicz ${ }^{\text {A-E }}$, Andrzej Smoleń ${ }^{\text {B-E }}$}

Josef Pilsudski Univesrity of Phsyical Education in Warsaw, Poland

ABSTRACT

New national and international societies that examine sports have been created and developed in Europe as well as on other continents. These societies, which examine the complex phenomena, issues, and questions concerning sports as seen from the different scientific points of view, are rooted in two main research directions: the natural sciences on the one hand, and the social sciences on the other.

The authors of the paper point to the significant and ongoing development of the social sciences of sport. In particular, the authors discuss the development of the sociology of sport, philosophy of sport, psychology of sport, pedagogy of sport, history of physical culture, sports and Olympics, the organization and management of sport, social and cultural foundations of tourism and recreation, social relationships associated with sports training and tactics, as well as the humanistic theories of Eastern martial arts.

The authors have listed several national, continental, and international scientific organizations that unite representatives of the aforementioned disciplines. However, the authors' main focus is on theoretical and organizational assumptions of the International Society for the Social Sciences of Sport, an organization founded in 2009.

The society's main objectives are to unite the particular social sciences of sport in one organized and scientific body (while maintaining the existing differences between the sciences); to enable the annual debate and exchange of views on the substantive and methodological matters; as well as to provide joint scientific publications connected with common work of the group and with the journal Physical Culture and Sport. Studies and Research.

The authors discuss the research and publishing activities of the Polish Society for Social Sciences of Sport, introducing the organization as an example of any future organization that could cooperate with the International Society for the Social Sciences of Sport.

KEYWORDS social sciences of sport, assumptions, organizational activities, conferences

\section{Origins and development}

The social sciences of sport, which constitute an important cognitive phenomenon of the second half of the twentieth century, are a branch of science that developed especially intensively in the last several decades of the twentieth century and at the beginning of the twenty-first century. Increased development was particularly noticed in the areas of sociology of sport; philosophy of sport; psychology of sport; pedagogy of sport; the history of physical culture, sport, and the Olympic games; sport organization and management; the 
social and cultural foundations of tourism and recreation; social relationships associated with sport training and tactics; as well as the humanistic theory of Eastern martial arts.

Testimony to this development can be seen in the large number of individual and collective monographs and textbooks, scientific journals initially published in the native languages of the country of publishing, and then - an already widespread procedure - in English. The fact that the publications are increasingly in English facilitates and fosters the ability to refer to them in subsequent publications. These publications are the result of academic findings; at the same time, they become an important and substantial inspiration for further research. The results of findings are submitted and then presented during local and international conferences organized on the continental level (for example, in the United States it is the North American Society for the Sociology of Sport; for Asia: the Pan-Asian Society of Sports and Physical Education; for Europe: the British Philosophy of Sport Association), on the intercontinental level (for South and Central America: ALESDE), and on the global level (for example, the International Association for the Philosophy of Sport; the International Association for the Sociology of Sport).

The aforementioned development resulted in the creation of corresponding academic units and curricula, programs of study related to them, and the various syllabuses that refer to them. In some cases, these units have decades-long tradition. Relevant chairs and departments were established in the structures of schools of higher education and universities. Subjects from the area of the social sciences of sport can be treated as being the same and interchangeable with subjects from the area of the humanities of sport. Two concepts contrary to the aforementioned viewpoint assume the diversity and autonomy of social sciences and human sciences, or the partial overlapping content of these two branches of science. Today, the social sciences of sport are along with the natural sciences (especially biological) of sport - the main educational subjects accompanying vocational and supplementary subjects connected with the education of physical education teachers, coaches, specialists in the field of tourism and recreation, and physical therapy specialists. The social sciences of sport create the necessary basis for education in institutions of higher education related solely or partly to the aforementioned groups of professionals. Aside from specialized departments in regular universities, there are independent universities in Poland and other countries, such as Germany, Norway and Russia,that have several decades of tradition of exclusively teaching the subjects of sport and physical culture.

\section{The existence of the social sciences of sport from the institutional and functional point of view}

The presence of the social sciences of sport in the scientific and academic community can be considered from the standpoint of the three institutional and organizational (structural and functional) conditions that must be met.

The first condition relates to the didactic characteristics of the social sciences of sport. Based on this condition, it is assumed that the considered science is included in the curricula of higher education, that is, it is taught, depending on the context, in lectures, seminars, and exercise classes. Students must attend these classes, for which they receive credit, and on that basis they must pass exams.

The second condition concerns academic research. This concerns empirical and theoretical investigations with social and humanistic overtones that are conducted in academic centers, including universities of physical education, and in strictly scientific institutions, as in the various national academies of sciences.

The third condition is localizing a particular unit in the institutional and organizational structure of an entire institution, that is, within the structure of a university or research institute. For example, the area of knowledge connected with the pedagogy of sport can be treated as the foundation for the functioning of the relevant educational and scientific institution or the research institution. It might apply, for instance, to the division of psychology of sport, the chair of psychology of sport, or other relevant institute or department.

From an institutional and organizational (structural and functional) point of view, the existence of a 
particular curriculum must first meet at least one of the two aforementioned conditions: the curriculum must be taught to become the subject of research. The third condition is not sufficient to be the general - and in this case main - rule for the presence of the social sciences of sport in the scientific and academic community. It is not enough to establish the unit with structural properties (that is, a unit as a part of bigger institution), where there is no curriculum that would imply the teaching activity or academic research activity with which the unit would be structurally and functionally connected. Thus, the third condition is fulfilled when it is necessarily and indispensably associated with at least one of the first two conditions. That is, when, for example, the department, chair or institute of sociology, psychology, history and philosophy of sport is associated with either the didactic activities or research activities in any or several of the abovementioned social sciences of sport. The mentioned entities (divisions, departments, chairs, institutes and so on) in the academic (university) centers in the country and abroad usually meet both the first and the second conditions.

The conditions presented above refer to the social sciences of sport that have fulfilled or have yet to fulfill the requirements of maturity and autonomy, both in terms of content (for example, the philosophy of sport in relation to the general philosophy and the related specific philosophies) and in the sphere of methodology (with regards to the particular methodologies related to the general methodology and other specific methodologies) (Kosiewicz, 2008/2009, pp. 5-38).

\section{Some remarks on the methodological and organizational status of the social sciences of sport}

In considering the status of the social sciences of sport from the perspective of the methodological types of sciences (Ajdukiewicz, 1985, pp. 287-313), it must be highlighted that the social sciences of sport are a component of the social sciences in general and the humanities in general (depending on the definition of these sciences), and a component of sport science (or, more broadly, the science of physical education), for which the methodological and formal status have not yet been regulated due to the diversity and existence of different specialized methodologies of those sciences.

Presentations during conferences, as well as numerous publications based on individual and team studies, including international teams studies, have showed that the social sciences of sport have neither a common nor clearly defined methodology that would be specific only to these sciences and that would have, as it were, a common denominator for all of the sciences. On the contrary, each of the sciences operates within its own methodology relating to the corresponding fundamental disciplines of the science, and - of course - to the main assumptions of the general methodology. For example, the philosophy of sport operates within the methodological assumptions of the methodology of philosophy, but it also refers to all its various fields and specific philosophies, as well as to the general and theoretical concepts, hypotheses, and substantive assumptions specific to these types of philosophies. A similar situation also occurs in other social sciences of sport including sociology of sport, psychology of sport, pedagogy of sport, and history of sport.

There is no doubt, however, that the social sciences of sport are a distinctive, autonomous part of sport science due to their specific content and detailed methodological conditions. They form, along with the natural sciences (especially the biological sciences), a vital and fundamental component of the science of sport.

Generally, it may be said that the natural sciences of sport (biological) mainly refer to the physical bodies of athletes, while the social sciences have in mind primarily the axiological, cultural, symbolic, aesthetic, and ethical reception of sporting effort. The social sciences of sport also refer to the pragmatic, purifying, escapist, ludic, hedonistic, epistemological, and recreational aspects of the variously understood competitive sport and sport for all.

Thus far, the representatives of the variety of social sciences of sport have organized separate national, continental, international and global societies. They have also organized conferences devoted exclusively to one discipline, such as the philosophy or sociology of sport, which, of course, has highlighted the distinctive identity of the particular discipline. Representatives of the natural sciences of sport have their separate 
organizations. Additionally, however, they have one unifying organization, the European College of Sport Sciences, which has existed since 1995 . This organization primarily attracts representatives from the natural sciences. Very few (in terms of the ratio of participants) social scientists attend conferences organized by this society. Presentations during the conferences organized by the European College of Sport Sciences are limited to 10 minutes, which is enough for a narrative presentation of empirical data in the field of natural science, but it is by no means sufficient time for a presentation of the usually complicated and complex considerations and findings in the field of social sciences.

The aforementioned fact became one of the reasons driving the development of a common organizational structure for the social sciences of sport. Thus, relatively recently (2009) the International Society for the Social Sciences of Sport (ISSSS) as well as the Polish Society for the Social Sciences of Sport (the Polish abbreviated name is: PTNSS) were established. The former organization was established at the beginning of 2009; the latter, at the end of 2009. Both organizations began operations after more than two years of registration procedures. The ISSSS has already organized four conferences: two in Warsaw in 2009 and 2010; one in Olomouc, Czech Republic, in 2011; and one in Koper, Slovenia, in 2012. Future conferences are already planned: in Porto (2013); Florence (2014); and in Kastamonu, Turkey (2015). All interested parties are invited to participate in the conferences.

The conferences that have already been held provided the opportunity to exchange interdisciplinary experience, to examine different and specific methods and assumptions. They inspired the comparison of a variety of topics, points of view, and methodological and theoretical considerations as well as their empirical, practical, research, and propositional implications and applications. The meetings led to interesting discussions and more or less in-depth scientific disputes that related to the relationship between the theoretical disciplines, such as philosophy of sport (compare: Kosiewicz, 2008/2009, pp. 5-38), or the history of sport and other sciences that are generally empirically oriented, for example, sociology, pedagogy, psychology or sports organization and management. The aforementioned disciplines are internally divided into the empirical and theoretical subjects. For example, in the sociology of sport we can distinguish between the empirical sociology of sport and the theoretical sociology of sport.

The work and achievements of Professor Zbigniew Krawczyk, PhD, are an excellent example of this type of dichotomy and relations occurring internally between the results of empirical and theoretical research (Kosiewicz, 2012, pp. 87, 89, 97-98). He is a great sociologist of sport with a global reputation who has led many research teams pursuing international empirical research projects. By the way, Professor Krawczyk's Selected Writings (Krawczyk, 2005, pp. 21-161) contains only the results of theoretical research. Indeed, Professor Krawczyk stated that the results of empirical studies - even those that are important and highly respected at the time there are published - quickly become irrelevant (just as with other authors' publications), and they lose importance. More immutable - which seems obvious from the point of view of the particular sociologies - and even more memorable and universal are theoretical texts of good quality (good quality in terms of content and methodology). The work of Zbigniew Krawczyk clearly demonstrates this.

The aforementioned claim, however, is not sufficient to assume the superiority of theoretical over empirical inquiry, whether in the area of social sciences of sport or in the natural sciences, including issues and questions related to sport. The superiority of theoretical research over empirical research cannot be proved in an irrefutable and definitive way. But neither can the opposite be proved: that is, the superiority of empirical over theoretical studies. It is not possible to obtain such proof from the perspective of epistemology, philosophy of science, general methodology, or comparative and axiological studies.

\section{Fourth World Conference of the International Society for the Social Sciences of Sport}

The $4^{\text {th }}$ World Conference of the International Society for the Social Sciences of Sport was held in Koper, Slovenia, from 5-7 October 2012. Representatives of science from several countries, including Czech Republic, Finland, Iran, Japan, Poland, Slovakia, Slovenia, Turkey, Hungary, and Italy attended the 
conference.

Especially impressive - for cognitive reasons - were the presentations of Professor Anna Pawlikowska-Piechotka, PhD, from Poland, Professor Lev Kreft, PhD, from Slovenia, Professor Ales Sekot, PhD, from the Czech Republic, Professor Patricia Zagnoli, $\mathrm{PhD}$, and Professor Emanuele Isidori, PhD, both from Italy, Professor Ajna Sarje, PhD from Finland, and Professor Jernej Pisk, PhD, from Slovenia.

Also, the presentation of Professor Jerzy Kosiewicz, PhD, provoked great interest. There were three main reasons for such interest: two were formal, and the third was related to the content of the presentation. First of all, it was the opening keynote speech. Second, it was the presentation of the President of the International Society for the Social Sciences of Sport. Third, for the first time Professor Kosiewicz presented one of his latest texts. It was devoted to Consideration of the Anti-doping Attitudes and Ethics. The text reflected on relations between the two concepts indicated in the title and their social occurrences.

In his article, Kosiewicz dealt with the essence, meaning, and identity of sport in the context of moral demands. He pointed out that sport could be located beyond moral good and evil. His 45-minute presentation referred to metaethical assumptions and included a unique metaethical disquisition that contained numerous examples of forbidden doping and high injury rates in professional sports, the so-called top-level sports. Professor Kosiewicz disputed the popular, common sense, and standard views that permeate the social sciences of sport. His goal was to more adequately determine the identity of sport in general and sport in its many realizations through a deliberately controversial dissertation. These sophisticated philosophical considerations on the topic of relations between morality and sport would undoubtedly broaden and deepen the reflection on the social context of sport and knowledge about sport in general. Professor Jerzy Kosiewicz pointed out, for example, that - in his opinion - the problem of doping in sport would not be solved with normative ethics, that is, with moralizing. He backed this claim by stating that normative ethics is relative, and it has a reduced ability to execute punishment. Normative ethics would never be sufficient to address the important and controversial social issue of doping. According to Professor Kosiewicz, this problem could however be solved in two ways: we could either impose consistent and strict legal penalization on the prohibited sports doping that would lead to administrative, civil and criminal consequences, or we can allow doping to be used in sport.

Professor Lev Kreft, the president of the European Association for the Philosophy of Sport, presented an excellent lecture on the topic Sport as a Drama. In his speech, he stressed that many features could characterize sport. Sport may be noble, attractive, and beautiful but also boring and ugly. When analyzing sport in the context of philosophical assumptions, especially taking in account the axiological and aesthetics assumptions of sport, there are many theatrical features that can be shown in sport.

The main and original message of this lecture was that, according to Professor Kreft, studies concerning sport should include the premise of everyday aesthetics, and in particular should include the category of "drama". Less important, in this area, is the category of beauty. The lecture's author considered the role and importance of drama in sport within its theoretical context as well as in the context of spontaneous daily communication. He took into consideration basic drama concepts: drama understood as an action, drama as a complex action, drama as a mimesis of action, and drama as a theatrical form and institution. Many actors with diverse and antagonistic goals work in the area of sport. Searching for analogies between theater and sport is important, according to Professor Kreft, but not the most important goal for science. To understand the drama of sport in action, it is necessary to describe and characterize the roles of the particular actors in the drama, their "body language," playing technique, including the way in which those actors mislead the arbitrators, and the audience observing sport performances.

Professor Aleś Sekot presented a paper on Fair play in the context of modern sport. He stressed that the sport as a social and cultural phenomenon fascinates people of different cultures and races, regardless of their political or religious orientation. The importance of sport in the world grows in the context of mutual understanding and respecting the rules of fair play. The modern Olympic games, which are a symbol of modern culture, has occupied a permanent place in constantly changing modern societies and civilizations. 
Sport also teaches responsible moral attitudes and fosters harmonious development of culture.

Professor Patrizia Zagnoli presented a paper entitled The Involvement of Spectators at Sporting Events: Motivations and Limitations. The paper was coauthored by Elena Radicchi, PhD. Spectator participation and activity at sporting events is a prerequisite for the success of a sport event. The involvement of the fans and supporters during the events may have a significant impact on the final results of sport competition. Meanwhile, in Italy recently there has been a significant reduction in people watching live sporting events (such as football and volleyball competitions). In today's world, a number of phenomena could cause a drop in the number of spectators at live events. Those factors could include economic and social problems, increased ticket prices, and possibilities for virtual access by potential viewers.

The situation requires sociological research (in terms of the factors that prevent or limit the number of spectators participating in sports events), marketing research, better organization, and better management of sports events. It would also be interesting to run comparative studies of the various sports across European countries.

Professor Emanuele Isodori presented an interesting paper on the topic Referee as a Teacher From the Hermeneutical and Pedagogical Perspective. The paper was coauthored by Arno Müller and S. Kaya.

Professor Isodori pointed out that in modern research, very little consideration is devoted to the sports referee. Professor Isodori decided to at least partially fill this gap. The authors of the paper used the methodology of the hermeneutic provenance. They studied in a broad historical perspective the role and function of a sports referee during the sports event, starting with the Olympics in ancient Greece. As a result of the conducted investigation, the authors stated that the referee held a significant ethical responsibility towards society in the area of shaping and preserving the intrinsic values of sport.

Studies have shown that refereeing requires comprehensive knowledge and methodology, including the ability to effectively enforce sporting rules. The referees themselves are often not fully aware of the educational and ethical function of their activity. Thus, providing good training for referees is extremely important not only to developing referees' technical skills but also in the context of developing their awareness of the axiological premises and humanistic values of sport.

Professor Ajne Sarja from Finland presented a paper on scientific speculation in the area of the history of sport. In wide-ranging historical research, the issue of sport is a problem that appears in a background of other problem. This is due to the fact that the traditional of historical research developed much earlier than historical reflection on the history of the sport. In a study on the history of sport, it is necessary to clarify the origins of all types of sport and the transformation of physical activities in different eras and cultures. The history of sport should have a significant importance in the culture of society: it should not be underestimated. In reality, however, this is often not the case. This is quite perplexing, given that much of the material in the history of sport cannot be denied due to the solid evidence. The historians' indifferent attitude to such material stems from the fact, as it seems, that the materials do not fit into the general approach and concepts for describing and explaining history. Meanwhile, photographs, conventions, rules, and programs for exercise and sport can be read in the same way as other systems of signs. For example, based on photographs of sporting events one can be taught a great lesson about life, culture, customs, and human relationships in history.

Professor Anna Pawlikowska-Piechotka gave a great and richly illustrated lecture entitled The Recreational and Urban Areas in Light of Social Expectations, coauthored by Karolina Sawicka.

Changes in the pace of our life and in the quality of life in recent years have been so large that it is possible to talk about "the revolution of free time". Society is becoming increasingly aware of the need for active recreation. The benefits of physical exercise are appreciated on a greater scale. Active recreation and sport require space, that is, recreational areas and facilities that would meet the needs and expectations of society. The spatial planning process must necessarily take into consideration the requirements of physical activity programs and modern trends in behavior connected to recreation among urban residents. 
The aim of the study conducted by the authors was to provide information for architects of urban recreation areas on current trends in the field of leisure activities of urban residents.

Professor Jernej Pisk from Slovenia presented an interesting paper on the subject of Sport in Light of Natural Sciences, Social Sciences, and Humanities. He stressed that in the area of sport, which is a subject of study of the natural sciences, social sciences and humanities, different scientific methods are used. The natural sciences and the social sciences of sport have a common quantitative research methodology. If we limit the scope of sport research to the issue of physical activity, then the natural sciences, with its empirical research methods, seem to be the most applicable for the scientific study of sport. However, we cannot rule out the important role of sport in modern societies. Hence, there is a need for the development of the social sciences of sport. The research on sport also has unquestionable importance the within the area of the humanities. A priori studies of sport, that is, considerations independent of the empiricism of the natural sciences, could reveal a deeper meaning of sport, as well as the objectives and values of sport. Sports science should therefore be developed in all three areas of research that are mentioned in the title of the presented paper.

The conference was very well prepared in terms of organization and program. It was decided that the next conference would take place in Portugal (Lisbon, 2013), Italy (Florence, 2014), and Turkey (2015).

\section{Second Conference of the Polish Society for the Social Sciences of Sport}

So far, only two conferences of the Polish Society for the Social Sciences of Sport were held - in contrast to the regular conferences organized by ISSSS. The first conference took place in 2011 in Targowiska - on the tourism and recreational property of the Obodyński family, perfectly situated and well prepared for this type of activity. It was hosted by the University of Rzeszów, under the supervision of Professor Kazimierz Obodyński, PhD, Dean of the Faculty of Physical Education. The conference resulted in the publication of two collective monographs, edited by Wojciech Cynarski, Jerzy Kosiewicz, and Kazimierz Obodyński: one in English, entitled Sport in the Context of Social Science, and the other in Polish, entitled Physical Culture and Sport in the Mirror of the Social Sciences.

The Second Conference of the Polish Society for the social sciences of sport was dedicated to the topic of Social Science's Relationship with Sport and Physical Culture: History, the Present, and the Future. The conference was held on 7-8 September 2012 in Olejnica, in an education and training center, the Water Sports Center of the University School of Physical Education in Wrocław. It was organized by the Department of Elements of Physiotherapy of the Faculty of Physiotherapy, University School of Physical Education in Wrocław. It was overseen and supervised by Tomasz Michaluk, PhD, and Krzysztof Pezdek, PhD. Dr. Michaluk chaired the Scientific Committee, and Dr. Pezdek chaired the Organizing Committee.

The conference had glamorous settings. The formal opening was conducted jointly by Małgorzata Mraz, PhD, the Associate Dean for Science of the Faculty of Physiotherapy, and by Professor Jerzy Kosiewicz, PhD, Chairman of the Polish Society for the Social Sciences of Sport. Just before the opening session, for the first time in the history of the Society a ceremony held was awarding the title of Honorary Member of the Polish Society for the Social Sciences of Sport to two outstanding personalities of Polish science: Professor Zbigniew Krawczyk, PhD, and Professor Józef Lipiec, PhD. They both laid the cornerstone for the development of social sciences in Poland, significantly contributing to the growth of these sciences in Poland and around the world. Professor Zbigniew Krawczyk contributed especially to the development of the sociology of sport and physical culture, while Professor Józef Lipiec to the philosophy of sport and physical culture. They authored many great books, which - using the philosophical arguments of Plato from Symposium and Phaedrus regarding the creativity of those who are gifted and marked by the divine inspiration - ensured the authors' ever-lasting fame and immortality. For many years, the work of these two professors has been an invaluable source of inspiration to stimulate further research.

The two-day conference was attended by 36 researchers (more than before) from several universities in Poland, including the University School of Physical Education in Poznań, University School of Physical 
Education in Wrocław, University of Physical Education in Warsaw, Physical Education Academy in Katowice, the Bogdan Jański Academy in Warsaw, University of Lower Silesia in Wrocław, the Jan Długosz University in Częstochowa, University of Białystok, University of Rzeszów, University of Zielona Góra, the Jan Kochanowski University in Kielce, University of Wrocław, the European School in Sopot, the Nicolaus Copernicus University in Toruń, and the Jan Amos Komeński State Higher Vocational School in Leszno.

Presentation that were of great interest included those by Professor Kosiewicz of the Józef Piłsudski University of Physical Education in Warsaw; by Tomasz Sahaj, PhD, from the University School of Physical Education in Poznań; by Krzysztof Pezdek, PhD, and Tomasz Michaluk, PhD, from University School of Physical Education in Wroclaw; by Artur Paśko, PhD, from the University of Białystok; and by Professor Piotr Godlewski from the University of Zielona Góra.

Professor Jerzy Kosiewicz presented a lecture dedicated to Considerations on Anti-doping and Ethics, that is, to relations between anti-doping, ethics, and social phenomena. A broader presentation of the content of this speech was presented above in the report from the conference in Koper.

Tomasz Sahaj, $\mathrm{PhD}$, in a paper entitled Euro 2012 in the Context of Contemporary Phenomena in Poland and Ukraine presented selected social phenomena that occurred before and during the European Football Championships in Poland and Ukraine. He pointed to the divergent goals and activities of various social groups that animated the studied phenomena. Among those groups were people who publicly expressed their support for the "philosophy of action" presented by the organizers of Euro 2012, as well as people who actively and strongly opposed such an attitude (for instance, the group of Ukrainian female students from "Ukraine's Ladies of Femen", or some Polish and Russian football hooligans). Some social groups organized on the occasion of this prestigious sporting event wanted to achieve mercantile objectives. An analysis of the attitudes and behaviors of different social groups with regards to the organization of "Euro 2012" once again confirmed the well-known thesis of Stanley D. Eitzen, that sport is a reflection of the problems of society and suffers from the same problems as the society in which it exists, though with less intensity.

An animated discussion provoked the joint presentation of Krzysztof Pezdek, PhD, and Tomasz Michaluk, PhD. They lecture concerned topic of Polish Football Association and the Problem of Exclusion Based on the Concept of Michel Foucault. The authors presented a controversial thesis that one of the management methods used by the activists of the Polish Football Association (in Polish: Polski Związek Piłki Nożnej, PZPN) is the management through exclusion. Thanks to this approach to management, the association strengthens its monopolistic position in the area of football in Poland. In relation to the public, the association is guided by utilitarian, legal and business criteria, while other criteria, including sport and moral criteria, which should have primary importance, are being ghettoized. Polish Football Association uses a policy of exclusion: sharing and rejecting those people and institutions that are not able to contribute to the financial success of the association. In relation to the opponents, the association uses various prohibitions; for the public, it promotes the image of success.

Artur Paśko, PhD, presented a very interesting paper to the audience entitled Sports Journalists and Media During the Stalinization of Poland. He talked about the pressure this working group was subjected to by the communist authorities.

The communist authorities sought power through the use of the press, radio and television as tools of class struggle to completely subjugate the object society. Media employees, including sports journalists, were recruited according to party lines. Party authorities, who used the support of the courses organized for sports journalists in cooperation with the Central School of Journalism of the Central Committee of the Communist Party (Central Committee of the Polish United Workers Party), sought to fill key journalistic positions with "their people", people with completely enslaved minds. Party and state authorities conducted a systematic and consistent control of the censorship of sports articles.

Despite the applied pressure on journalism, the governing party was never fully satisfied with the work of sports journalists, even to the end of Stalinism. Some journalists - despite harassment and severe 
oppression from the party and state authorities - kept their independent views and expressed them during the events of the October 1956, calling for the implementation of changes in the system of physical culture in Poland and for organizing a nationwide meeting of sports activists.

Professor Piotr Godlewski in his speech dealt with the problems of the origins and development of liberal arts-related and society-related topics within physical education sciences.

He stressed that, while Polish research in the area of physical education sciences (later called the physical culture sciences) has at least a hundred-year-old tradition, the processes of incubation, development, and achieving autonomy happened mainly in the post-war years. In the second half of the 1980s, thanks to contacts in the world of science and scientists, Polish science assimilated, to a limited extent, the universal patterns and modernized research methodologies in thematic groups related to physical education. The research standards underwent slow modernization.

According to Professor Godlewski, understanding the processes of incubation, development, achieving autonomy, and self-identification related to the physical culture sciences requires an explanation of key issues: the process of giving ideological character, the impact of social determinants, the process of the physical education sciences (later called the physical culture sciences) gaining pragmatic overtones, the process of searching for the sciences' own methodological paradigms, and the solid theoretical foundation of empirical and normative research.

Among other presentations, a well-deserved attention was given to the lectures of Professor Eligiusz Małolepszy, PhD, from the Jan Długosz University in Częstochowa, Professor Jan Ożdziński from the European School in Sopot, Dorota Pawlik, PhD, from the Physical Education Academy in Katowice, Katarzyna Salomon-Krakowska, PhD, from University School of Physical Education in Wrocław, Teresa Drozdek-Małolepsza, PhD, from the Jan Długosz University in Częstochowa, Jakub Mosz, PhD, from the University of Physical Education in Warsaw, Joanna Śniadek, PhD, from the Jan Amos Komeński State Higher Vocational School in Leszno, Radosław Kossakowski, PhD, from the University of Gdańsk, and Krzysztof Kubala, PhD, from the University of Rzeszów.

Professor Eligiusz Małolepszy presented in an orderly, systematic, and inspiring way the development of historical studies, achievements, and current State of Research on the History of Physical Education and Sport in the Countryside in Poland in the years 1918-1939. He took interest in an extremely important research problem regarding the great variety of Polish society of the interwar period.

Professor Małolepszy remarked that research on the history of physical education and sport in the Polish countryside in the years 1918-1939 was mainly conducted during the first decade of the twenty-first century. He presented and discussed works with the highest exploratory value, dedicated mainly to rural youth organizations, youth associations, and social societies. He also drew the listeners' attention to physical education infrastructure in the countryside and to the presence and diverse manifestations of interest in physical culture shown in press, especially the rural press. Professor Małolepszy justified the need for development and greater funding for supporting research on the history of physical education and sport in rural schools, rural folk high schools, and among ethnic minorities.

Professor Jan Ożdziński presented a paper on The Structure of the Needs and Interests in the Rational Use of Free Time. He stressed that the subject is particularly important in the context of shaping the positive behaviors of the Polish society, while building the solid foundations for market economy. The need to be competitive in the labor market requires entrepreneurial and innovative behavior, which includes the formation of new standards of behaviors among young people who wish to succeed amidst the new political realities. The results of empirical research on the physical activity of young generation in their free time indicates that much needs to be done in this area. It is becoming necessary to take new initiatives at the government level with the participation of scientific authorities.

The presentation given by Dorota Pawlik, PhD, entitled Social Determinants of Sport Among the Maoris in New Zealand, caught people's attention because of the different cultural context of the discussed issues. The author presented the results of the field studies conducted in 2007 in New Zealand among the 
representative sample of the Maori people. The author confirmed that the studied community showed aboveaverage interest in sport and physical education. While passive ways of spending leisure time are preferred among inhabitants of developed countries, in New Zealand society, where the Maoris are an integral part, sporting activity is an essential way of spending their free time.

Katarzyna Salomon-Krakowska, $\mathrm{PhD}$, presented a very knowledgeable and philosophically sophisticated lecture on the topic Physical Activity: A Noble or Vulgar Effort? The Vital Values in the views of Max Scheler and José Ortega y Gasset. In her discourse, Professor Salomon-Krakowska presented problems associated with values assigned to the body in an original and surprising cognitive perspective. She concluded that the way to avoid extreme positions when thinking about physicality (on one hand the Platonic tradition and, on the other hand, the contemporary soma-centric concept) and to mediate between the two extremes is to consider the properties of the body in the context of Scheler's concept of nobility. The clash of values of nobility and vulgarity leads - according to Scheler - to the crystallization of vital values. The author of the presentation characterized the rank, role and specificity of the vital values and their impact on the human activity. She stressed that Scheler clearly distinguished between vital values and hedonic or utilitarian values. The vital values include the widely understood physical education, health promotion and ecology. In Scheler's concept, vital values are not reduced to hedonic values. They are autonomous and occupy a prominent place in the hierarchy of values. In the final part of her presentation - essential for the whole presentation - the author talked also about the philosophy of José Ortega y Gasset.

Teresa Drozdek-Małolepsza, $\mathrm{PhD}$, talked about a very important problem in her presentation, one that requires thorough and in-depth study: Tourism of Women in Poland in the Years 1918-1939. She remarked that the interwar development of tourism in Poland was characterized by more numerous and more active participation of women in various forms of tourism. The dynamic development of tourism seen among women occurred in direct connection with the activities of various governmental and non-governmental organizations that promoted tourism, as well as the equality and autonomy of women, who sought their rights to access tourist attractions and physical activities.

In the interwar period, women had a big impact on the Polish Tourist Association (Polskie Towarzystwo Krajoznawcze), the Union of Polish Tourist Associations (Związek Polskich Towarzystw Turystycznych), and the Polish Health Resorts Association (Związek Uzdrowisk Polskich). The study showed that women particularly enjoyed adventure tourism. They undertook a number of difficult and risky travel challenges without the participation of men.

The issue of tourism from a literary perspective was addressed by Jakub Mosz, PhD. His speech was entitled Zbigniew Herbert's Theory of Journey. The author presented an attempt to reconstruct the theory of journey from the content of Herbert's work, explaining issues related to the experience objectives, and cognitive aspects of tourism, as well as the role of senses in a tourist's autotelic perception and experience of the word. This perception and experience is unusual, ceremonial (secular sacrum), and it contrasts dramatically with the profane everyday life and everyday experience. The author performed analytical procedures with truly maieutic overtones to extract from and discover the interest in tourism that can be found in (with Socratic midwifery applause) Zbigniew Herbert's work. Herbert appreciated the cultural foundation of tourism; he distanced himself from the postmodern consumerism that reduces contemporary tourism to mass consumption of tourism products.

Joanna Śniadek, PhD, talked about issues related to the organization and management of physical education. She dedicated her presentation to issues of Financing Physical Education from the Budgets of Local Governments in Poland in the Years 2000-2011. The social benefits of the development of this area in human life confirm the need for institutional and financial support for the participation of Poles in physical education. Local authorities have an important role to play in this regard. They are obliged by law to promote physical activity among urban and rural residents. On the basis of an analysis of budgets of local governments in Poland, it was proved that the share of expenditure on physical culture in 2000-2010 was characterized by a positive trend. Starting in 2011, however, the level of funding for physical education from 
government budgets is declining. This trend diverges from society's expectations, indicating a need to increase the level of funding for physical education found within budgets of local governments.

Radosław Kossakowski, $\mathrm{PhD}$, brought an important contribution to the reflection on the behavior of sports fans. In his speech, entitled Emile Durkheim Alive Forever? The Usefulness of the Concept of Mechanical and Organic Solidarity in the Studies of Sports Fans, the author sought answers to the question of whether there is mechanical solidarity in the world of sport and its area. He claimed that the concept of mechanical solidarity could be used to describe the community of the most zealous football fans, because this community could be characterized by a low degree of individualism, strong social control, and collective morality. This community operates within the frame of a specific distribution of tasks: some fans are involved in organizing and establishing cheering activities during games and organizing trips to matches; others are devoted to "hooligan activity". With this specific "job distribution", community values are the most important: solidarity and mutual support, especially during clashes with the police. Some behaviors of the most fervent football fans suggest that this community can be one of the last "bastions" of a highly integrated society in which group values dominate over individual values.

Krzysztof Kubala, $\mathrm{PhD}$, presented a paper, prepared jointly with Marcin Obodyński, $\mathrm{PhD}$, on healthrelated behavior of youth participating in martial arts in Poland, Czech Republic, and in the United States. He emphasized that the results are only a part of complex international research (Polish-Czech-American) on the social determinants of martial arts training. The research is being conducted under the supervision of Professor Wojciech Cynarski, PhD, within the socio-anthropological section of International Martial Arts and Combat Sports Scientific Society (IMACSSS). The paper presented the scientific and organizational results of the aforementioned section of IMACSSS.

The aforementioned conferences of the International Society for the Social Sciences of Sport, and the conferences of the Polish Society for the Social Sciences of Sport confirmed the desirability of such meetings and the need for their continuation. They enable - similar to conferences devoted to individual disciplines of the social sciences of sport - to improve knowledge related to interpersonal relationships that occur during the sports activities. In the assessment of such meetings, it should be remembered that both high-performance sport and sport for all contribute - as cultural and economic social phenomena - to the strategic objectives of the European Union, such as solidarity, health and prosperity.

\section{REFERENCES}

Ajdukiewicz, K. (1985). Metodologiczne typy nauk /Methodological types of sciences/. In K. Ajdukiewicz, Język i poznanie /Language and cognition/ (pp. 287-313). Warsaw: PWN.

Kosiewicz, J. (2008/2009). Philosophy of Sport from the Institutional, Content-related, and Methodological Viewpoints. Physical Culture and Sport. Studies and Research, XLVI, 5-38. DOI: 10.2478/v10141-009-0001-5.

Kosiewicz, J. (2012). Philosophy of Sport In Poland: Observations. Physical Culture and Sport. Studies and Research, LIV, 86-102. DOI: 10.2478/v10141-011-0010-7.

Krawczyk, Z. (2005). Selected Writings. In J. Kosiewicz (Ed.), Sport, Culture and Society (pp. 21-161). Warsaw: Józef Piłsudski University of Physical Education.

\section{AUTHOR'S ADDRESS: $\quad$ Jerzy Kosiewicz}

Department of Philosophy and Sociology

Josef Pilsudski University of Physical Education in Warsaw

34 Marymoncka str.

00-968 Warsaw

Poland

Email:jerzy.kosiewicz@awf.edu.pl 